\title{
Cisto de inclusão conjuntival gigante associado a pterígio - Relato de caso
}

\author{
Giant conjunctival inclusion cyst associated with pterygium-Case report
}

\author{
Vanderson Glerian Dias ${ }^{1}$ \\ Marcos Paulo Martins ${ }^{2}$ \\ Ana Karina Teixeira Bezzon ${ }^{3}$ \\ Jonathan Seiji Ag'uni ${ }^{4}$ \\ Rodrigo Cavalheiro ${ }^{4}$
}

\section{RESUMO}

O cisto de inclusão conjuntival gigante (CICG) pode causar sérios defeitos estéticos além de incompleto fechamento palpebral. Os autores apresentam paciente de 57 anos com cisto de inclusão conjuntival gigante em olho direito associado a pterígio. Discute-se sobre os aspectos fisiopatológicos da formação do cisto de inclusão e sobre as possíveis técnicas cirúrgicas.

Descritores: Cistos/fisiopatologia; Cisto/cirurgia; Conjuntiva/patologia; Pterígio/cirurgia; Doenças orbitárias/cirurgia; Relato de caso

\section{INTRODUÇ̃̃̃O}

São vários os tipos de tumores conjuntivais, dentre eles, nevus, melanomas, papilomas, displasias, carcinomas de células escamosas, linfomas, tumores inflamatórios, cistos, sarcoma de Kaposi e outros. A suspeita diagnóstica deve ser feita através do exame biomicroscópico por um oftalmologista experiente e familiarizado com tumores conjuntivais, porém o diagnóstico é histopatológico ${ }^{(1)}$.

Segundo o "Stedman's Medical Dictionary"(2), cisto significa saco anormal contendo gás, fluido ou material semi-sólido, com um arcabouço membranoso. Muitos são os locais onde os cistos podem estar presentes (pálpebras, segmento anterior, conjuntiva, órbita, etc). $\mathrm{O}$ aparecimento da formação cística pós-trauma ${ }^{(3)}$ ou cirurgias de estrabismo ${ }^{(4)}$, catarata $^{(5)}$, enucleação $^{(6)}$ ou colocação de "buckle" escleral ${ }^{(7)}$, está bastante documentado na literatura.

Os cistos de inclusão conjuntival são derivados de uma inclusão do epitélio conjuntival para dentro da substância própria formando uma cavidade central cística após a proliferação das células epiteliais. O revestimento do cisto é composto por epitélio conjuntival não ceratinizado ${ }^{(7)}$.

O cisto de inclusão conjuntival gigante (CICG) pode causar tanto sérios defeitos estéticos quanto alterações anátomo-fisiológicas da conjuntiva e das pálpebras que levam, na maioria das vezes, ao incompleto fechamento palpebral.

O objetivo deste estudo é discutir as possíveis alterações relacionadas com a patogenicidade dessa entidade mórbida no pré e pós-operatório.

\section{RELATO DO CASO}

Paciente RCF, do sexo feminino, de 57 anos, procurou o serviço de oftalmologia do Hospital Universitário (HU) da Universidade do Oeste Paulista (UNOESTE), em maio de 2003, referindo um tecido de crescimento progressivo cobrindo o olho direito (OD) com início a mais de 20 anos, além 
de "carne crescida" em olho esquerdo (OE). Negou trauma ou cirurgia ocular e relatou ter feito cirurgia para câncer de útero há muitos anos. Em relação aos antecedentes familiares, afirmou que a mãe possui pterígio em ambos os olhos (AO).

Ao exame apresentava a seguinte acuidade visual (AV) para longe sem correção: em OD, conta dedos (CD) a $40 \mathrm{~cm}$; e em OE, CD a $1 \mathrm{~m}$. Pela biomicroscopia, pterígio nasal grau IV em OD e grau III em OE, além de massa cística grande em OD envolvendo toda a região medial da conjuntiva bulbar até conjuntiva forniceal superior e inferior. As margens medial, superior e inferior não eram totalmente visíveis (Figura 1).

Não foi possível realizar refratometria, fundoscopia e nem mesmo tonometria de aplanação devido ao grau de acometimento ocular pelas lesões conjuntivais, porém constatou-se pressão intra-ocular (PIO) normal à digitopressão.

Ao "cover test" apresentou esotropia (ET) alternante com preferência pelo $\mathrm{OE}$, porém o exame foi muito prejudicado pela dificuldade visual da paciente.

Após uma semana da consulta no ambulatório de oftalmologia a paciente foi submetida a exérese do cisto e pterígio do OD, através da técnica de esclera nua, enviando material para exame histopatológico o qual comprovou ser cisto de inclusão conjuntival (fragmento membranáceo, creme e translúcido, de 0,8 $\mathrm{x} 0,3 \mathrm{~cm}$ ). A figura 2 (foto à esquerda) mostra o aspecto da paciente no pós-operatório (PO) imediato ainda com blefarostato.

A paciente ainda apresentava formação cística em região dorsal (sobre o músculo trapézio), demonstrada na figura 2, foto à direita.

A figura 3 ilustra o pós-operatório de 3 meses da paciente após exérese de pterígio bilateral e cisto em OD. Somente em OE foi realizada exérese de pterígio com transplante autólogo de

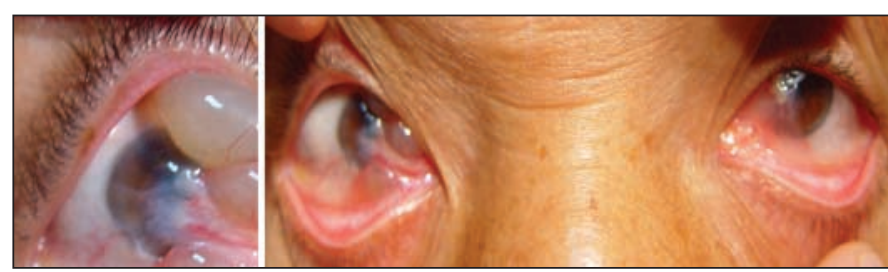

Figura 1 - Fotos das regiões oculares da paciente com cisto de inclusão conjuntival gigante

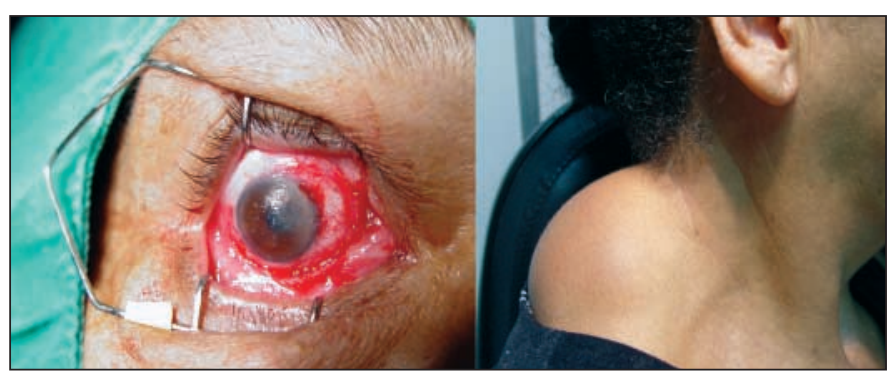

Figura 2 - À esquerda, foto do PO imediato de exérese do cisto $e$ pterígio do OD. Á direita, formação cística em região dorsal (sobre o músculo trapézio) conjuntiva (Técnica de Kenyon ${ }^{(8)}$ da região superior do mesmo olho devido a escassez de tecido conjuntival bulbar em OD.

A AV para longe com correção tornou-se 20/100 em OD e 20/30 em OE. Indicou-se correção cirúrgica da esotropia (ET $40^{\Delta}$ para longe com correção - Krinsky), porém a paciente recusou, achando sua estética ótima.

\section{DISCUSSÃO}

Em um trabalho realizado na Malásia, o local mais freqüente de tumores ou lesões parecidas com tumores oftalmológicos foi a pálpebra (51\%), seguida pela conjuntiva (32\%), na qual se inclui o CICG. Retinoblastoma foi o tumor maligno mais freqüente (10 casos) e a lesão parecida com tumor mais comum foi o cisto dermóide $(16 \text { casos })^{(9)}$.

Diagnósticos mais precisos, em relação às lesões císticas e tumorais da conjuntiva bulbar, podem ser feitos com ajuda da ultra-sonografia de alta freqüência. Esse exame ajuda identificar as margens de segurança (extensão do tumor), se há ou não invasão escleral ou se o músculo reto medial está encarcerado, principalmente em relação às lesões císticas mediais ${ }^{(10)}$.

Na ausência da ultra-sonografia como método para identificação das margens de segurança para exérese do cisto conjuntival, pode-se usar a injeção intracística de indocianina verde ${ }^{(11)}$.

A associação do cisto de inclusão com outras patologias conjuntivais, como pterígio, pingueculite, conjuntivite vernal e granuloma piogênico ${ }^{(12)}$, além de traumas da superfície ocu$\operatorname{lar}^{(3)}$, já é bem conhecida. Em um dos trabalhos analisados, foram encontrados 5 casos de cisto de inclusão pelo exame histopatológico de um total de 55 casos de pterígio avalia$\operatorname{dos}^{(12)}$. Isso demonstra a possibilidade fisiopatológica da formação do cisto de inclusão estar relacionada à infiltração de células inflamatórias, podendo inclusive explicar o fato da aparição dos cistos estar mais relacionada ao trauma ou póscirurgias oculares.

Sabemos que, se a formação cística depende de processos inflamatórios, o sistema imunológico é o responsável pela deflagração desses processos. Fatores individuais, como doenças auto-imunes, contribuem para que a resposta imunológica se altere e resulte em processos imunológicos inadequados e prejudiciais aos tecidos, explicando a formação cística exagerada nesta paciente, já que a mesma relata não ter tido traumas ou feito cirurgias oculares anteriormente.

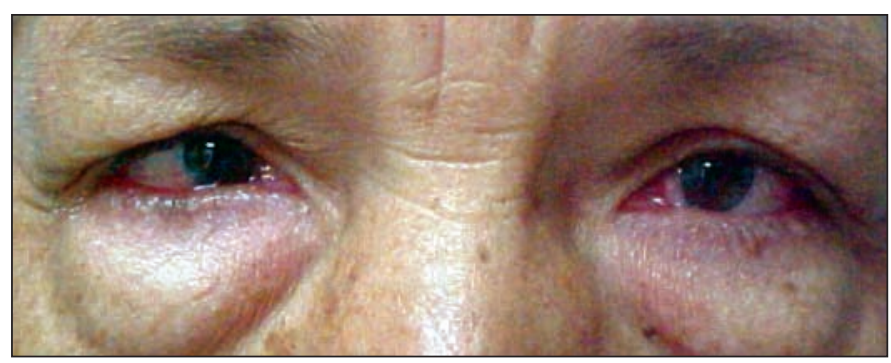

Figura 3 - Foto do $3^{\circ}$ mês de PO de exérese de pterígio AO e CICG em OD 
A atenção do oftalmologista deve estar voltada à estética do paciente tanto quanto às possíveis restrições musculares que tumores conjuntivais possam ocasionar. A exérese mostrou ser uma técnica adequada para retirada do cisto de inclusão conjuntival, mesmo que muitos cistos possam involuir espontaneamente ou com uso de antiinflamatórios. A técnica de termocauterização também pode ser usada com resultados ótimos, já que a morte das células epiteliais destrói o cisto ${ }^{(13)}$. Já o uso somente da drenagem tem demonstrado recidivas freqüentes na prática.

A reconstrução da superfície conjuntival após a exérese de grandes cistos ou tumores conjuntivais pode ser feita de várias maneiras, dentre as quais: a técnica de transplante de conjuntiva autóloga ${ }^{(8)}$ do olho contralateral e o uso da membrana amniótica $^{(14)}$. No futuro, no entanto, materiais biossintéticos talvez poderão ser incorporados ao arsenal cirúrgico para a reconstrução conjuntival, como por exemplo, o uso da biomembrana de látex ${ }^{(15)}$, a qual merece investigação científica maior.

\section{ABSTRACT}

The giant conjunctival inclusion cyst (GCIC) can cause serious esthetic defects and incomplete eyelid closure. The authors present a 57 -year-old patient with a giant conjunctival inclusion cyst in the right eye with an associated pterygium. The physiopathologic aspects of the inclusion cyst formation and the possible surgery techniques are discussed.

Keywords: Cysts/physiopathology; Cysts/surgery; Conjunctiva/ pathology; Pterygium/surgery; Orbital diseases/surgery; Case report

\section{REFERÊNCIAS}

1. Cursino JW, Santo RM, Cursino SRT. Patologia ocular . In: Conselho Brasileiro de Oftalmologia. Manual . Rio de Janeiro: Cultura Médica; 2002. p.36-8.

2. Stedman TL. Cyst. In: Stedman TL. Stedman's medical dictionary. $26^{\text {th }}$ ed. Baltimore: Williams \& Wilkins; 1995. p.429.

3. Marigo FA, Finger PT, McCormick SA, Iezzi R, EsaKi K, Ishikawa H, et al. Anterior segment implantation cysts. Ultrasound biomicroscopy with histopathologic correlation. Arch Ophthalmol. 1998;116(12):1569-75.

4. Metz HS, Searl S, Rosenberg P, Sterns G. Giant orbital Cyst after strabismus surgery. J AAPOS. 1999;3(3):185-7.

5. Finger PT, McCormick SA, Lombardo J, Tello C, Ritch R. Epithelial inclusion cyst of the iris. Arch Ophthalmol. 1995;113(6):777-80.

6. Jünemann A, Holbach LM. Epitheliale Riesenimplantationszyste 50 jahre nach Enukleation ohne Orbitaimplantat. Kin Monatsbl Augenheilkd. 1998;212 (2):127-8.

7. Johnson DW, Bartley GB, Garrity JA, Robertson DM. Massive epitheliumlined inclusion cysts after scleral buckle. Am J Ophthalmol. 1992;113(4): 439-42.

8. Kenyon KR, Wagoner MD, Hettinger ME. Conjunctival auto graft transplantation for advanced and recurrent pterygium. Ophthalmology. 1985:92(11): 1461-70.

9. Reddy SC, Das PK. Tumors and tumour-like lesions of the eye: a clinic pathological study from Hospital University Sains Malaysia. Malays J Pathol. 1996; 18(2):113-20.

10. Finger PT. Giant conjunctival inclusion cysts. New York: Eye Cancer Network. [cited 2000 Nov 21]. Available from: http://www.eyecancer.com/ conditions/Cases/Case6/Case6.html

11. Kobayashi A, Saeki A, Nishimura A, Segawa Y, Shirao Y, Kawasaki K. Visualization of conjunctival cyst by indocyanine green. Am J Ophthalmol. 2002; 133(6):827-8

12. Suzuki K, Okisaka S, Nakagami T. [The contribution of inflammatory cell infiltration to conjunctival inclusion cyst formation]. Nippon Ganka Gakkai Zasshi. 2000;104(3):170-3. Japanese.

13. Hawkins AS, Hamming NA. Thermal cautery as a treatment for conjunctival inclusion cyst after strabismus surgery. J AAPOS. 2001;5(1):48-9.

14. Tseng SC, Prabhasawat P, Lee SH. Amniotic membrane transplantation for conjunctival surface reconstruction. Am J Ophthalmol. 1997;124(6):765-74.

15. Pinho ECCM, Sousa SJF, Schaud F, Lachat JJ, Coutinho-Netto J. Uso experimental da biomembrana de látex na reconstrução conjuntival. Arq Bras Oftalmol. 2004;67:27-32.

\title{
ABO ELETRÔNICO
}

\section{A versão eletrônica dos Arquivos Brasileiros de Oftalmologia com textos completos está disponível em:}

- ABO - Arquivos Brasileiros de Oftalmologia http://www.abonet.com.br

\author{
- SciELO - Scientific Electronic Library Online \\ http://www.scielo.org
}

- Free Medical Journals - http:/www.freemedicaljournals.com 